\title{
PROBLEMS OF EVACUATION
}

\begin{abstract}
A SPECTS of evacuation problems are discussed in recent articles in the Political Quarterly and the Quarterly Review, which malke a number of useful suggestions for their solution. Reviewing the working and present position of the evacuation scheme in the Political Quarterly, Mr. A. D. K. Owen suggests that in Scotland uncertainty concerning the financial aspects of evacuation played a considerable part in deterring many people from going away or permitting their children to leave vulnerable areas. He considers that more effective publicity, directed to the poorer sections of the population, relating to the financial implications of evacuation might have resulted in a more satisfactory response.

While in the reception areas the situation is in many ways not unsatisfactory, it is difficult to see how the evacuation scheme can be successfully rebuilt in the absence of compulsory powers. Mr. Owen suggests that certain districts within the existing evacuation areas should be scheduled as specially dangerous-all places, for example, within a certain distance of military or naval targets, shipbuilding yards, docks or important railway junctions-and children of sehool age prohibited from living in them save in very exceptional circumstances. He also suggests that the law of school attendance should be amended so as to prevent parents from bringing their children home from reception areas without good reasons.
\end{abstract}

The first measure would involve transferring all schools serving the prohibited districts to reception areas, and the second would make it possible to plan ahead with some assurance that the population for which plans are being made would not melt away before they matured. Schools in those parts of the evacuation areas which lie outside the prohibited districts should be opened as soon as they have been given reasonable protection, but a fresh approach made to parents in these areas to persuade them to allow their children to be evacuated or re-evacuated.

Capt. Frederic Evans, in the Quarterly Review, directs attention rather to measures which might be taken in the reception areas to organize new life for evacuees within the strange environment to which they have been taken. He emphasizes the importance of balancing out school accommodation and staffs, the development of specialized accommodation for difficult children, clinics, recreation and other purposes. Holiday camps, youth hostels, and village halls could all offer important contributions, and if well organized might contribute to a closer wedding of the town to the country, with far-reaching and beneficial consequences to the whole nation.

Psychological and financial problems have to be faced and the careful planning of the medical services in the country is of special importance. Their staffing and provision pre-suppose a national service. Capt. Evans urges that the considerable expenditure involved in the various social services required to solve these problems must be incurred or we may find the War has been fought in vain.

Dr. W. A. Robson's article, "Evacuation, Town Planning and the War", is concerned with the wide issues which are opened up by the evacuation not merely of school children, but also of civil servants, business houses, ete., and the imperative need for some central control and planning if chaos is not to result from the indiscriminate location not merely of industry in the reception areas but also from the tremendous demand for premises and land by the civil and military authorities. The demands of the War Office and the Air Ministry for camps and aerodromes must be met without question or delay ; but it would be the gravest mistake to permit all these new and necessary constructions arising from these as well as from civil needs, and also the consequences of evacuation, to take place in utter confusion or on the basis of laissez-faire, and with a complete disregard of the peace-time situation which will follow the War.

For this reason, and because our war-time exigencies are strangely consistent with socially desirable peace-time purposes, Dr. Robson views with such alarm the abandonment by the Government of the reports of the Royal Commission on the geographical distribution of the industrial population. Town and country planning should now acquire a new and more important status and be placed in the hands of a strong central department competent not only to deal with the special needs of the Service departments and the Government offices, but also to take over the long overdue task of directing the location of industry and formulating a national plan for the whole country.

\section{AIR CONDITIONING}

$\mathrm{A}^{\mathrm{N}}$ $\mathrm{N}$ abstract of a paper on "Air Conditioning" read by W. Chambers to the North Midland Section of the Students of the Institution of Electrical Engineers and published in the Institution's Journal of December gives a clear account of the objects to be attained by air-conditioning and of the methods by which it can be done.

The object is to maintain in a building an atmosphere that is most beneficial to the health of the occupants or which is most suitable to the process of manufacture carried on therein. To maintain these conditions, it is necessary to control the heat content or temperature, the purity, the moisture content (humidity) and the distribution of the air. A ventilating scheme in which the air is filtered, comfortable in temperature and adequate in volume, is sometimes considered entirely satisfactory, and little if any attention is paid to its moisture content, although the latter has a great effect upon the comfort of the human body. 